strain nas becoming intolerable." The italics are mine ; they serve to show that recently there have been difficulties of such a nature as to cause such an article as that which I had written and that the demands, far from being of " a most limited extent," had given rise to an immense amount of harm and produced a strain that was becoming intolerable. I fail to ind anything in my report on the subject stronger or even as strong as this. The Leeds Express of March 11th, in a leader on Mr. Benson Jowitt's speech, confirms my view, for it holds that "there is no smoke without fire, and THE LANCET Commissioner did not evolve from his own imagination the complaints he set forth. Nor can it be overlooked that two of the Workpeople's Hospital Fund representatives on the infrmary board intimated, in speaking to resolutions adopted yesterday, that members of their fund had expressed dissatisfaction as to certain matters." The same paper adds : "It would be idle to deny, however, that the impression that people well able to pay for proper medical treatment have utilised the resources of the infirmary bas caused considerable heartburnings among working-men subscribers. They do not begrudge the sums they contribute-sums which, though small, represent a certain -amount of self-sacrifice; nor do they claim special and exceptional privileges. But they resent the idea that people far better able to contribute than themselves enjoy advantages of the institution without cost; while in some cases workmen who subscribe (even on a small scale) have not received quite the consideration or courtesy, as they think, that is desirable."

This is precisely one of the most important points I attempted to bring forward. I was dealing with hospital abuse. If there were no abuse the workmen subscribers would have no excuse for claiming rights. But it is natural that subscribers should complain if they are refused admission to the infirmary, when others who do not subscribe and are as well or better off than themselves are admitted. It is "wrong of subscribers to claim the right of admission, but this wrong arises naturally out of another and greater wrong, the toleration of hospital abuse. Then it was also natural that, finding such abuse would not or could not be abolished, the suggestion should have gone forth of converting the infirmary into a provident clab. I did not approve of this idea, but I recorded the fact that it existed. It would be a means of equalising conditions and of compelling those who do not subscribe to subscribe. Though there is a great deal to say against such a proposal it does seem to me quite natural that under actual circumstances it should have been made; but again I repeat that I did not mean to support in any way this solution of the difficulty. The Torkshire Post, however, in its leader of March 11th, denies that help has been refused at the infirmary to those who pay in a regular and systematic manner, while it is freely given to those who do not pay at all, and declares that " such a state of affairs does not exist." I was told, on the contrary, that there had been a considerable amount of discussion concern. ing, for instance, the case of a very active committee-man of 'the Workpeople's Hospital Fund. In consequence of a fall this person suffered from some internal injury. His club doctor failed to effect a cure, and one day, when this committeeman brought to the hospital a sum of $\$ 7$ odd which he had collected, he sought to obtain a second opinion from one of the surgeons on the infirmary staff. This advice was refused. Doubtless the refusal was, in one sense, quite justifiable; but the committee-man in question pointed out that many other patients were receiving advice who were in a better position than himself. Why, it was asked, should he pay and collect money for them when he could not get advice for himself. This is the sort of incident which occasions the present trouble, and that trouble is serious and may lead to very far-reaching consequences. Then, again, I am blamed for saying that the workmen "justly maintain that they do not receive from the infirmary anything like an equivalent for what they give to the infirmary." In the previous sentence $I$ bad mentioned that the cost of in-patients was . $£ 1$ 1s. $8 \frac{1}{2} d$, and of out-patients $1 s .3 \frac{3}{4} d$. per week. By this I did not mean that the workmen ought to receive an equivalent, but that their calculation was accurate when they said they said they did not receive an equivalent. Such a consideration is important, because if the present dissatisfaction were to greatly increase it might be financially possible for the workpeople to withdraw their subscriptions from the infirmary and establish a hospital of their own on provident lines. It is in view of this danger-doubtless very small at present, but which may grow-that the need of prerenting the hospital abuse which engenders such ideas has become especially urgent. I endeavour to make my reports as free as possible from any sort of advocacy; but if $I$ do advocate anything it is the prevention of hospital abuse. The virulent controversy that my remarks on the Leeds Workpeople's Fund has occasioned suggests that I succeeded in putting my finger on a sore place. The somewhat wild, impassioned, and contradictory manner in which attempts have been made to refute the description $I$ gave of the grievance likewise suggests to my mind that that grievance is more serious and menacing than I had at first supposed. I am, Sirs, yours faithfully,

March 16th, 1897. YOUR SPFCIAL CoMMISSIONER.

\section{"THE MEDICAL STAFFS OF HOSPITALS AND HOSPITAL ABUSE."}

\section{To the Editors of THE LANCET.}

SiRS,-Mr. Burdett's letter in THe LANCET of March 13th calls for a few remarks. First, with respect to a conference, Mr. Burdett is aware that my association proposed to hold one this summer, and that he wrote so strongly on the question that we thought it wise to postpone the question for a time. We are of opinion that the subject of hospital reform should be discussed not only from a professional, but from a lay point of view. It is perfectly true, as you have stated, that the medical and surgical staffs of hospitals are to a certain extent responsible for the present unsatisfactory condition of the out-patient department, but, on the other hand, the managing committees are surely the proper authorities to take the initiative in the work of reform. These committees must be $e_{t}$ aware of the crowds that attend the out-patient and casualty departments, and they must also be aware that their officials base their appeals to the public on the number of people who are thus attended. It is not improbable that representations on this subject have already been made by some of the staffs to the hospital authorities.

Mr. Burdett will, no doubt, be glad to hear that we are asking the Royal College of Physicians of London to make an investigation into the question. That College would be in a position to speak with more authority than any voluntary committee that might be formed in London. There appears to be one error in Mr. Burdett's letter. He states that Sir William Fergusson's committee recommended that medical officers attending the out-patients should be paid. I have carefully looked through the columns of THE LANCET, but I have failed to find this fact recorded. I believe some members of the committee did propose such a recommendation, but it was not agreed to. In conclusion, it will be gratifying to Mr. Burdett to know that we shall shortly publish the report of a sub-committee of our association which was asked to make an inquiry into the working of the special hospitals of the metropolis. As far as regards the general hospitals I believe I am not far wrong when I state that inquiries into the circumstances of patients are made at four only-viz., St. Bartholomew's Hospital, the London Hospital, the Great Northern Hospital, and the Royal Free Hospital, and that the number of nero patients is limited at two only-viz., St. Thomas's Hospital and St. George's Hospital. St. Mary's Hospital has, as you probably are aware, recently appointed a special medical officer to sift the cases before they are seen by the assistant physicians and surgeons.

March 15th, 1897. I am, Sirs, faithfully yours,

T. GARRETT HORDER,

Honorary Secretary to the Hospital Reform Association.

\section{To the Editors of THF LANCET.}

SIRs, - Mr. Burdett's letter is one of unusual importance to the profession. I venture, therefore, to suggest that every member of the profession should take an early opportunity of coming to your office to sign the petition to the Royal College of Physicians of London at present lying there. As we have no representative body who can undertake the consideration of the matter, the College of Physicians certainly appears to be the body who should undertake the duty of stating the case of the profession upon the matter of hospitals. Mr. Burdett is no doubt to some extent quite correct in attributing the present condition of affairs to the hospital staffs. The College of Physicians has the monopoly of hospital appointments in London upon the medical side, 
and it is therefore not unreasonable to expect of that body something in return for that monopoly.

I am, Sirs, your obedient servant,

Hatfield, March 15th, 1897.

Lovelt Drage.

\section{"THE UNDIMINISHED MORTALITY FROM PUERPERAL FEVER IN ENGLAND AND WALES." \\ To the Editors of THE LANOET.}

SIRS,-Dr. Rentoul endeavours to throw discredit on my statistics. It is one thing, however, to "challenge" statements; it is quite another to disprove them. The only point in his letter which even appears to justify his indictment is where he accuses me of not understanding the figures I am dealing with. If that were so it would, of course, seriously affect the value of my conclusions. But in the in stance given it is Dr. Rentoul wbo has fallen into error. For although it is quite true, as he says, that where the death, from whatever cause, has taken place witbin a month of delivery the Registrar-General directs that this fact be mentioned in the certificate, it is equally true that in his returns the deaths dircetly connected with childbirth are placed in a separate table. Hence my statement is quite correct-viz, that deaths occurring from causes not directly connected with childbirth are, in the statistics from which I quote, left out of account.

Dr. Rentoul asks for "light" on the number of women who are ill in the hospitals but who do not die. So far as the General Lying-in Hospital is concerned, this information has been furnished in the most ample manner in a paper read before the Obstetrical Society by Dr. Boxall. It is also readily available with regard to all the more important con tinental lying-in hospitals.

Dr. Rentoul speaks of the statistics of the lying-in hospitals as fallacious, and in support of this allegation he refers to and repeats the statements he made on the subject before the Select Committee on the Registration of Midwives. Those statements have been refuted over and over again. The impression produced by Dr. Rentoul's evidence on the members of the Select Committee can be easily ascertained on reference to the Blue-book. On page 41 of the minutes of evidence it will be seen that towards the close of his long hearing Dr. Rentoul gave an answer that elicited the following remark from his questioner: "This is one of the many statements that you have made in the course of your evidence of a very grave nature which have been entirely unsupported by anything I could call evidence." After this estimate of his statements before the Committee it is surprising that $D_{n}$. Rentoul should dare to refer to them again.

Dr. Rentoul scoffs at antiseptics. Ary man who can do this (I do not say any man who disbelieves in the $m$, but any man who can scoff at them) in the face of the mass of evidence now available is beyond the reach of argument. There is such a thing as what my friend Sir William Roberts calls reason-blindness. Persons who suffer from this not very uncommon affliction are inaccessible to argument and impervious to the plainest facts. It does not make the least difference to Dr. Rentoul that his statements have been repeatedly disproved. Witness his often refuted blunder about one person in every fifteen dying in their first confinement. Here in his letter of to-day it crops up again, as though the statement had never been denied or even called in question.

I have no hope of being able either to convince Dr. Rentoul or to silence him. The object of my letter is simply to warn such of your readers as are not acquainted with his methods not to be misled by the sophistries with which his letter abounds.

I am, Sirs, yours sincerely,

Chas. J. Cullingworth.

Manchester-square, W., March 13th, 1897.

\section{“A QUESTION FOR AN ESTHETISTS.'}

To the Editors of THE LANCET.

SrRs,-Mr. Clement Lucas's question is one of transparent importance and may present the novelty to some which it appears to do to him. As a matt $r$ of fact, the danger of infection, and the manifestiy filthy practice of using a blood. stained or vomit-polluted inhaler has appealed to me and, $x$ should say, to all thoughtful anzsthetssts for many years. The inhalers in common use-Clover's for ether and various. forms of Junker's for chloroform-have been made so as to admit of absolute sterilisation. In the first case the face-piece can be constructed of celluloid or metal, either substance: being capable of beirg made clean, and the more common leather and rubber face-piece is equally cleansable by water and carbolic acid. Mr. Lucas's suggestion with regard to the employment of toughened glass has been anticipated. I recently described such a face-piece, suggested originally by Vajna of Budapest, in the Year-book of Treatment, p. 171, ${ }^{1}$ and drew emphatic attention to its value from the point of view of the surgeon who practises aseptic operations. Previously to this Mr. Krohne had made metal frames covered with domett or flannel, which were usec with Junker's bottle and bellows. This face-piece can be boiled or baked, and by having two or three a freshly sterilised one can be employed for each case. As, then, the inhaler for ether made at my suggestion by Messrs. Majer and Meltzer and the chlorotorm inhalers described above admit of the most rigid sterilisation, it can only be hoped that those who have not already realised the importance of Mr. Lucas's warning will do so and adopt the means already at hard for obviating the dangers which must follow the use of dirty inkalers. I do not suggest that the inhalers I have specified are the only ones which are clean, probably many others exist, nor do I enter upon the question whether or no pulmonary infection can occur from inhaling an aræsthetic from a dirty inhaler. It is sufficient that common sense and accumulated knowledge combine to warn us that danger must follow the use of filthy instruments, whether they be human hands, scalpels, or inhalers for anæsthetics. I may add that the anæsthetist and his clothing are possible sources of infection which should not be overlooked. Those whose lines fall among infections or septic cases are not ideal anæsthetists from this point of view. Students who anæithetise under my supervision are compelled to wear a clean linen coat and wash their hands and their apparatus before each case is commenced.-I am, Sirs, y our obedient servant,

DUdLex BuXToN, M.D., B.S Lond., M.R.C.P., Anæsthetist, University College Hospital.

Mortiraer-street, W., March 17th, 1897.

\section{"THE PROPOSED LEGISLATION FOR HABITUAL DRUNKARDS."}

\section{To the Editors of THE LANCET.}

Srns,- The Bill introduced last year into the Reichstag authorising the seclusion of habitual drunkards in separate asylums for drunkards not having yet been passed into law, the Landtag (Provincial Parliament) of Lower Austria, in accordance with a detailed report of Director Tilkowsky setting forth that there were in the five lunatic asylums in Lower Austria 107 suitable patients who might be at once transferred to a separate asylum for drunkards, has resolved in the session just closed to form a department for drunkards in an unoccupied portion of the penitentiary at Kornenburg, this resolution to take effect during the current year. How great a number of habitual drunkards are accommodated in the five lunatic asylums and penitentiary of Lower Austria may be gathered from statistics, which show that during the past ten years 2389 alcoholists have been received in to the above-mentioned five lunatic asylums, and that during the last six years 1200 individuals morally ruined by habitual abuse of spirituous liquors have been provided for in the penitentiary at Kornenburg. The Provincial Parliament of Lower Austria in a note urging the Government to pass the above-mentioned Bill, specially refers to the circumstance that Great Britain is at present occupied with the question of secluding habitual drunkards, and that the English Government, acting. on a report of the departmental committee, has decided to extend and amend materially the provisions of the Habitual. Drunkards Act. May a satisfactory result soon be arrived at by the English Parliament!

I am, Sirs. yours faithfully,

Dr. Fr. Schlangenhausen.

Villach, Carinthia, March 13th, 1897. 